\title{
Mean Platelet Volume is Associated with Pancreatic $\beta$-Cell Dysfunction in Nondiabetic Patients with Coronary Artery Disease
}

\author{
Xiliang Zhao',* \\ Xiaoli $\mathrm{Li}^{2, *}$ \\ Quan $\mathrm{Li}^{\prime}$ \\ Yicong Ye' \\ Yong Zeng'
}

'Center for Coronary Artery Disease, Division of Cardiology, Beijing Anzhen Hospital, Capital Medical University, Beijing, 100029, People's Republic of China; ${ }^{2}$ Department of Cardiology, Rugao Hospital of Traditional Chinese Medicine, Jiangsu, 226500, People's Republic of China

*These authors contributed equally to this work
Correspondence: Yicong Ye

Center for Coronary Artery Disease,

Division of Cardiology, Beijing Anzhen

Hospital, Capital Medical University,

Beijing, 100029, People's Republic of

China

Tel +86 I86 0121 6917

Email yicongye@163.com
Purpose: Mean platelet volume (MPV) is an indicator of platelet activation. Pancreatic $\beta$ cell dysfunction is one of the fundamental defects contributing to the development of type 2 diabetes. The aim of this study was to assess the relationship between $\beta$-cell dysfunction and MPV in nondiabetic patients with coronary artery disease (CAD).

Patients and Methods: A total of 1143 consecutive nondiabetic patients (874 males and 269 females; mean age $60.0 \pm 10.3$ years) with CAD were recruited for this analysis. All patients were individuals who underwent coronary angiography with a suspicion of CAD. Homeostatic model assessment 2 (HOMA2) of $\beta$-cell function (HOMA2- $\beta \%$ ) was performed, and $\beta$-cell dysfunction was defined by a HOMA2- $\beta \%$ in the lowest quartile.

Results: MPV was significantly higher in CAD patients with $\beta$-cell dysfunction than in controls $[(10.6 \pm 1.0) f 1$ vs $(10.0 \pm 1.0) f l, P=0.011]$. According to the multiple regression model, pancreatic $\beta$ cell dysfunction was independently associated with MPV $(\beta=0.210, \mathrm{P}=0.006)$ and age $(\beta=0.008$, $\mathrm{P}=0.028$ ).

Conclusion: MPV was significantly elevated in nondiabetic CAD patients with $\beta$-cell dysfunction compared to patients with normal $\beta$-cell function.

Keywords: mean platelet volume, pancreatic $\beta$-cell function, coronary artery disease

\section{Introduction}

Mean platelet volume (MPV) is an indicator of platelet activation, which plays an important role in the pathophysiology of cardiovascular diseases. ${ }^{1,2}$ MPV is one of the platelet function indices that reflects the average size of platelets in the blood and the rate of their production by bone marrow. ${ }^{3}$ In comparison to smaller platelets, larger platelets have more extended pseudopodia and granules, aggregate more rapidly with collagen and express more glycoprotein IIb/IIIa receptors. ${ }^{2,4}$

Elevations in MPV have been reported in patients with coronary artery disease (CAD). ${ }^{5,6}$ Additionally, elevated values of MPV are also associated with the incidence of diabetes mellitus (DM) and impaired fasting glucose (IFG). ${ }^{7}$ Insulin resistance and $\beta$ cell dysfunction are fundamental defects contributing to the development of type 2 diabetes. ${ }^{8}$ Previous studies have shown a correlation between insulin resistance and MPV in nondiabetic patients with $\mathrm{CAD}^{4}$ and in patients with gestational diabetes mellitus. ${ }^{9}$ However, to the best of our knowledge, whether there is an association between $\beta$-cell dysfunction and MPV in nondiabetic CAD patients is unclear.

The homeostatic model assessment (HOMA) of $\beta$-cell function and insulin resistance was first described in 1985, and HOMA2 is the correctly solved 
computer model and one of the most broadly accepted models used for assessing $\beta$-cell function and insulin resistance from basal glucose and insulin or C-peptide concentrations in clinical practice and clinical research with a large sample size. ${ }^{10}$ The purpose of this study was to investigate the relationship between $\beta$-cell dysfunction and MPV in nondiabetic patients with CAD.

\section{Patients and Methods Study Population}

Patients presenting to the Center for Coronary Artery Disease, Beijing Anzhen Hospital, Capital Medical University for coronary angiography between March 2018 and October 2019 were recruited consecutively into the study. The indication for coronary angiography was either the presence of typical angina or positive results of noninvasive screening tests for myocardial ischemia. All patients received a maintenance dose of aspirin (100 mg, once daily) and P2Y12 inhibitor (clopidogrel, $75 \mathrm{mg}$, once daily or ticagrelor, $90 \mathrm{mg}$, twice daily) in the hospital. The major exclusion criteria were as follows: a history of DM, symptoms of severe heart failure (New York Heart Association class III and above), severely impaired hepatic or renal function before the procedure (serum alanine aminotransferase $>2.5$ times the upper limit of normal and serum creatinine $>2.0 \mathrm{mg} / \mathrm{dL}$ ), a history of malignancy and acute or chronic infection. The study protocol complied with the Declaration of Helsinki and was approved by the Institutional Review Board of Beijing Anzhen Hospital (IRB number: 2018075X). Informed consent from all participants or their legal proxies was granted.

\section{Coronary Angiography}

Selective coronary angiography was performed with a single 5-French OPTITORQUE ${ }^{\circledR}$ Tiger coronary diagnostic catheter or by the Judkins technique using 6-French right and left heart catheters in multiple projections. Coronary angiograms were reviewed by two experienced interventional cardiologists without knowledge of the patients' clinical information and laboratory measurements. CAD was defined as $>50 \%$ stenosis in major epicardial vessels.

\section{Assessment of $\beta$-Cell Function}

Venous blood samples were obtained through venipuncture during the morning hours after an overnight fast of at least
8 hours. Fasting glucose levels were measured with an enzymatic method, and fasting insulin levels were measured using the competitive radioimmunoassay method. $\beta$ Cell function was estimated by the computer-based model of HOMA2- $\beta \%$, and insulin resistance (IR) was estimated by HOMA2-IR. HOMA2- $\beta \%$ and HOMA2-IR were calculated from fasting glucose levels $(\mathrm{mmol} / \mathrm{L})$ and fasting insulin levels $(\mu \mathrm{U} / \mathrm{mL})$ using the online calculator provided by the University of Oxford Diabetes Trial Unit (http://www.dtu.ox.ac.uk/homacalculator/). ${ }^{10} \beta$-Cell dysfunction was defined by a HOMA2- $\beta \%$ in the lowest quartile, and insulin resistance was defined by a HOMA2IR in the highest quartile. ${ }^{11}$

\section{Demographic, Clinical and Laboratory Assessments}

Data related to demography, lifestyle, medical history, and the medication of each patient were collected. Demographic variables included age and sex. Behavioral risk factors included body mass index (BMI, weight in kilograms divided by the square of height in meters) and cigarette smoking. Clinical and laboratory data included (1) presentations of CAD: stable angina (SAP), unstable angina (UA), non-ST-segment elevation myocardial infarction (non-STEMI), and ST-segment elevation myocardial infarction (STEMI); (2) medical history of hypertension, ischemic stroke, myocardial infarction, percutaneous coronary intervention (PCI) or coronary artery bypass graft(CABG); (3) baseline white blood cell (WBC) count, hemoglobin (HGB) level, platelet (PLT) count, MPV, serum lipid levels (total cholesterol [TC], low-density lipoproteincholesterol [LDL-C], high-density lipoprotein-cholesterol [HDL-C], triglycerides [TGs]), and creatinine levels. MPV was measured in a blood sample collected in bipotassium EDTA tubes within 30 min to prevent EDTA-induced swelling. An automatic blood counter (Mindray Bio-Medical Electronics, BC-6800 Plus, Shenzhen, China) was used for whole blood analysis; (4) major medications administered in the hospital: angiotensin-converting enzyme inhibitors (ACEIs), angiotensin receptor blockers (ARBs), $\beta$-blockers, calcium channel blocking agents (CCBs), and statins; and (5) diabetes-related indices: fasting glucose, insulin, and hemoglobin A1c (HbA1c).

\section{Statistical Analysis}

Continuous variables are presented as the mean \pm standard deviation or medians with interquartile ranges and were compared using Student's $t$-test or the Mann-Whitney 
$U$-test, as appropriate. Normality was tested by the Kolmogorov-Smirnov test. Noncontinuous and categorical variables are expressed as frequencies and percentages. The chi-square test was used to evaluate categorical data when the expected cell counts were $>5$; otherwise, Fisher's exact test was used. Spearman correlation analysis was performed to assess the correlation between MPV and the examined variables, including HOMA2- $\beta \%$. Forward stepwise multivariate linear regression analysis was used to evaluate the relationship between $\beta$-cell dysfunction and MPV after adjusting for potential confounders, including age, sex, BMI, smoking status, presentation of CAD, baseline levels of $\mathrm{WBC}, \mathrm{HGB}$, PLT, TG, LDL-C, and creatinine and indices of glucose metabolism. For the multivariate logistic regression analysis, factors with a $\mathrm{p}$ value $<0.05$ in the univariate analysis were selected. A 2-tailed $\mathrm{p}$ value $<0.05$ was considered statistically significant. All statistical analyses were performed with SPSS Statistics 20.0 (SPSS, Inc., Chicago, IL, USA).

\section{Results}

A total of 1143 consecutive nondiabetic patients with CAD were ultimately enrolled in this study. The baseline data of the studied participants are shown in Table 1. The mean age and BMI of the patients were $60.0 \pm 10.3$ years and $25.1 \pm 2.6 \mathrm{~kg} / \mathrm{m}^{2}$, respectively. Approximately threequarters of patients were male, and one-third were smokers/ex-smokers. The prevalence of hypertension, ischemic stroke and previous myocardial infarction was $66.5 \%, 10.3 \%$ and $9.7 \%$, respectively. All patients included in this study were divided into two groups according to the HOMA2- $\beta \%$ median and interquartile range: the pancreatic $\beta$-cell dysfunction group (Q1: HOMA2- $\beta \%=12.0-81.4, \mathrm{n}=285$ ) and normal pancreatic $\beta$ cell function group (control group, Q2 Q4: HOMA2- $\beta \%$ $=81.5-302.1, \mathrm{n}=858$ ). The clinical and laboratory characteristics of the CAD patients stratified by quartiles of HOMA2- $\beta \%$ are shown in Table 1. Patients with decreased $\beta$-cell function were older and had a lower BMI and lower TGs and creatinine levels than control subjects. For diabetes-related indices, patients with $\beta$-cell dysfunction had higher levels of fasting glucose and HbA1c and lower levels of insulin and HOMA2-IR than control group patients.

The hematological parameters of the CAD patients with pancreatic $\beta$-cell dysfunction and normal pancreatic $\beta$-cell function are shown in Table 2. Patients with pancreatic $\beta$-cell dysfunction tended to have lower $\mathrm{WBC}$, HGB and PLT levels and higher MPV levels [(10.6 \pm 1.0$) \mathrm{fl}$ vs $(10.0 \pm 1.0) \mathrm{fl}, \mathrm{P}=0.011]$ than controls. In addition, the association between MPV and traditional cardiovascular risk factors was assessed. This comparison suggested that MPV was higher in females than in males $(10.5 \pm 0.9 \mathrm{fL}$ vs $10.0 \pm 1.0 \mathrm{fL}, \mathrm{P}=0.002$ ) and higher in smokers/ex-smokers than in nonsmokers $(10.6 \pm 1.0 \mathrm{fL}$ vs $10.0 \pm 1.0 \mathrm{fL}$, $\mathrm{P}=0.040$ ). Spearman correlation analysis revealed that MPV was poorly correlated with age $(\mathrm{r}=0.092, \mathrm{P}=0.007)$, the TGs level $(\mathrm{r}=0.077, \mathrm{P}=0.025)$ and the HOMA2- $\beta \%$ level $(\mathrm{r}=-0.171, \mathrm{P}=0.038)$. In a multiple regression model, pancreatic $\beta$-cell dysfunction was independently associated with MPV $(\beta=0.210, \quad \mathrm{P}=0.006)$ and age ( $\beta=0.008, P=0.028)$, but sex, smoking status and serum TGs were not significantly associated with MPV after adjusting for other confounding factors.

\section{Discussion}

The main finding of this study is that patients with $\beta$-cell dysfunction measured by HOMA2- $\beta \%$ have significantly higher MPV values than control subjects with normal $\beta$ cell function among nondiabetic patients with CAD.

There is accumulating evidence linking MPV with CAD and its comorbidities (eg, DM and IFG). MPV has been found to be significantly increased in patients with diabetes, impaired fasting glucose and insulin resistance ${ }^{4,7}$ and is also a useful prognostic marker in patients with CAD. ${ }^{12,13}$ However, no previous study has examined the relationship between MPV and $\beta$-cell dysfunction, which is one of the principal metabolism defects of type 2 diabetes. Thus, this study was designed to investigate the contributions of $\beta$-cell dysfunction to MPV in nondiabetic patients with CAD. We showed that $\beta$-cell dysfunction was an independent risk factor for increased MPV. To improve $\beta$ cell function, platelet activation should be decreased, which would consequently decrease morbidity and mortality. In accordance with prior studies, our study also found that MPV was significantly correlated with age. ${ }^{14}$

Chronic exposure to excessive glucose and lipids can lead to $\beta$-cell dysfunction and/or cell death. ${ }^{15}$ Previous studies have shown that a decline in $\beta$-cell function may begin even in normal glucose tolerant individuals. ${ }^{16}$ However, over time, in a subset of individuals, $\beta$-cell compensation cannot be sustained, and hyperglycemia or DM develops. ${ }^{15}$ There are multiple possible mechanisms underlying the increased MPV levels associated with $\beta$ cell dysfunction. First, platelets have insulin receptors that 
Table I Demographic and Clinical Characteristics of the CAD Patients by HOMA2- $\beta \%$ Categories

\begin{tabular}{|c|c|c|c|c|}
\hline & $\begin{array}{l}\text { Overall } \\
(n=|| 43)\end{array}$ & $\begin{array}{l}\text { Pancreatic } \beta \text {-Cell } \\
\text { Dysfunction } \\
(n=285)^{a}\end{array}$ & $\begin{array}{l}\text { Normal Pancreatic } \\
\beta \text {-Cell Function } \\
(\mathrm{n}=\mathbf{8 5 8})^{\mathrm{b}}\end{array}$ & p value \\
\hline Male, m (\%) & $874(76.5 \%)$ & $224(78.6 \%)$ & $650(75.8 \%)$ & 0.328 \\
\hline Age, y & $60.0 \pm 10.3$ & $62.5 \pm 9.1$ & $59.2 \pm 10.5$ & $<0.001$ \\
\hline $\mathrm{BMI}, \mathrm{kg} / \mathrm{m}^{2}$ & $25.1 \pm 2.6$ & $24.0 \pm 2.7$ & $25.4 \pm 2.5$ & $<0.001$ \\
\hline \multicolumn{5}{|l|}{ Medical history, n, (\%) } \\
\hline Hypertension & $760(66.5 \%)$ & $179(62.8 \%)$ & $581(67.7 \%)$ & 0.128 \\
\hline Previous stroke & $121(10.6 \%)$ & $29(10.2 \%)$ & $92(10.7 \%)$ & 0.795 \\
\hline Previous myocardial infarction & III (9.7\%) & $25(8.8 \%)$ & $86(10.0 \%)$ & 0.536 \\
\hline Previous percutaneous coronary intervention & $206(18.0 \%)$ & $46(16.1 \%)$ & $160(18.6 \%)$ & 0.340 \\
\hline Previous coronary artery bypass graft & II (I.0\%) & I (0.4\%) & $10(1.2 \%)$ & 0.222 \\
\hline Presentation of CAD & & & & 0.716 \\
\hline Stable angina & $443(38.8 \%)$ & $113(39.6 \%)$ & $330(38.5 \%)$ & \\
\hline Unstable angina & $537(47.0 \%)$ & $129(45.3 \%)$ & $408(47.6 \%)$ & \\
\hline Non-ST-segment-elevation myocardial infarction & $93(8.1 \%)$ & $22(7.7 \%)$ & $71(8.3 \%)$ & \\
\hline ST-segment-elevation myocardial infarction & $70(6.1 \%)$ & $21(7.4 \%)$ & $49(5.7 \%)$ & \\
\hline Current or previous smoking, n (\%) & $392(34.3 \%)$ & 99 (34.7\%) & $293(34.1 \%)$ & 0.885 \\
\hline \multicolumn{5}{|l|}{ Baseline laboratory evaluation } \\
\hline Total cholesterol, mmol/L & $3.8 \pm 0.9$ & $3.9 \pm 0.9$ & $3.8 \pm 1.0$ & 0.099 \\
\hline LDL-C, $\mathrm{mmol} / \mathrm{L}$ & $2.2 \pm 0.8$ & $2.3 \pm 0.8$ & $2.2 \pm 0.8$ & 0.085 \\
\hline $\mathrm{HDL}-\mathrm{C}, \mathrm{mmol} / \mathrm{L}$ & $1.0 \pm 0.3$ & $1.0 \pm 0.4$ & $1.0 \pm 0.3$ & 0.665 \\
\hline Triglycerides, $\mathrm{mmol} / \mathrm{L}$ & $1.5 \pm 0.9$ & $1.3 \pm 0.7$ & $1.6 \pm 1.0$ & $<0.001$ \\
\hline Creatinine, $\mu \mathrm{mol} / \mathrm{L}$ & $72.0 \pm 15.6$ & $69.3 \pm 14.4$ & $72.9 \pm 15.8$ & 0.001 \\
\hline \multicolumn{5}{|l|}{ Major medication administered in hospital } \\
\hline Clopidogrel, n, (\%) & 747 (65.4\%) & $188(66.0 \%)$ & $559(65.2 \%)$ & 0.803 \\
\hline ACEls, n, (\%) & 205 (17.9\%) & $44(15.4 \%)$ & 161 (18.8\%) & 0.205 \\
\hline ARBs, n, (\%) & 291 (25.5\%) & $60(21.1 \%)$ & $231(26.9 \%)$ & 0.058 \\
\hline$\beta$-blockers, n, (\%) & 797 (69.7\%) & $200(70.2 \%)$ & 597 (69.6\%) & 0.850 \\
\hline CCBs, n, (\%) & $215(18.8 \%)$ & 45 (15.8\%) & 170 (19.8\%) & 0.132 \\
\hline Statins, n, (\%) & II 25 (98.4\%) & 279 (97.9\%) & $846(98.6 \%)$ & 0.406 \\
\hline \multicolumn{5}{|l|}{ Glucose indices } \\
\hline Fasting glucose, $\mathrm{mmol} / \mathrm{L}$ & $5.2 \pm 0.8$ & $5.6 \pm 1.1$ & $5.1 \pm 0.6$ & $<0.001$ \\
\hline $\mathrm{HbAlc}, \%$ & $5.8 \pm 0.5$ & $5.9 \pm 0.6$ & $5.8 \pm 0.5$ & 0.001 \\
\hline Insulin, $\mu \mathrm{U} / \mathrm{mL}$ & $9.3(6.7-13.2)$ & $5.7(4.6-7.2)$ & $10.7(8.3-14.6)$ & $<0.001$ \\
\hline HOMA2-IR & $1.21(0.87-1.72)$ & $0.77(0.60-0.97)$ & $1.39(1.08-1.90)$ & $<0.001$ \\
\hline
\end{tabular}

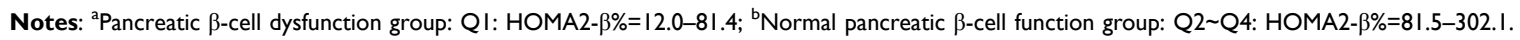

Abbreviations: BMI, body mass index; CAD, coronary artery disease; LDL-C, low-density lipoprotein-cholesterol; HDL-C, high-density lipoprotein-cholesterol; ACEls, angiotensin-converting enzyme inhibitors; ARBs, angiotensin receptor blockers; CCBs, calcium channel blocking agents; PPIs, proton pump inhibitor; HOMA2-IR, Homeostatic model assessment 2 of insulin resistance.

participate in the regulation of platelet functions, ${ }^{17}$ and impairment of the insulin receptor signaling pathway and a procoagulant state caused by $\beta$-cell decompensation may play a role in the occurrence of platelet hyperreactivity. ${ }^{18}$ Second, insufficient insulin secretion caused by $\beta$-cell dysfunction may result in vessel injury, and decreased vascular endothelial production of prostacyclin and nitric oxide may promote increased platelet activities. ${ }^{19}$ Third, inadequate insulin fails to suppress hepatic glucose production and enhance peripheral glucose uptake, leading to hyperglycemia, which can increase platelet reactivity via osmotic effects. $^{20}$

Platelets play an important role in thrombus formation and contribute to other processes, such as atherosclerosis, inflammation and autoimmunity. ${ }^{21,22}$ Measuring MPV is a simple and easy method of accurately assessing platelet 
Table 2 Comparison of the Hematological Parameters of the CAD Patients with Pancreatic $\beta$-Cell Dysfunction and Normal Pancreatic $\beta$-Cell Function

\begin{tabular}{|l|l|l|l|l|}
\hline & $\begin{array}{l}\text { Overall } \\
(\mathbf{n = 1} \text { I43) }\end{array}$ & $\begin{array}{l}\text { Pancreatic } \boldsymbol{\beta} \text {-Cell } \\
\text { Dysfunction }(\mathbf{n}=\mathbf{2 8 5})^{\mathbf{a}}\end{array}$ & $\begin{array}{l}\text { Normal Pancreatic } \boldsymbol{\beta} \text {-Cell } \\
\text { Function }(\mathbf{n}=\mathbf{8 5 8})^{\mathbf{b}}\end{array}$ & p value \\
\hline WBC, $\times 10^{9} / \mathrm{L}$ & $6.9 \pm 1.8$ & $6.5 \pm 1.6$ & $7.0 \pm 1.8$ & $<0.001$ \\
HGB, g/L & $142 \pm 15$ & $138 \pm 14$ & $143 \pm 15$ & 0.001 \\
PLT, $\times 109 / \mathrm{L}$ & $222 \pm 59$ & $213 \pm 54$ & $225 \pm 60$ & 0.002 \\
MPV, fL & $10.2 \pm 1.0$ & $10.6 \pm 1.0$ & $10.0 \pm 1.0$ & 0.011 \\
\hline
\end{tabular}

Notes: ${ }^{a}$ Pancreatic $\beta$-cell dysfunction group: Q1: HOMA2- $\beta \%=12.0-81.4$; ${ }^{\mathrm{b}} \mathrm{Normal}$ pancreatic $\beta$-cell function group: Q2 Q4: HOMA2- $\beta \%=81.5-302.1$.

Abbreviations: WBC, white blood cell; HGB, hemoglobin; PLT, platelet; MPV, Mean platelet volume.

function and appears to correlate more closely with platelet function than the platelet count alone. MPV is elevated when both platelet production and destruction are increased, and MPV elevation is the first indication of platelet activation. ${ }^{13,23}$ In comparison to smaller platelsts, larger platelets are functionally, metabolically and enzymatically more reactive, produce more thromboxane A2, aggregate more readily in vitro, contain denser granules, show increased expression of membrane receptors ${ }^{23}$ and do not respond well to antiplatelet therapies, such as aspirin and clopidogrel. ${ }^{24}$

For the measurement of platelet function, there is no goldstandard method showing the real state of "hyper" or "hypo" reactivity that can be used as a reliable marker of high risk in disease settings. ${ }^{25}$ Common laboratory tests, including light transmission aggregometry, thromboelastography, flow cytometric vasodilator-stimulated phosphoprotein phosphorylation assay and thromboxane $\mathrm{B}(2)$ generation, have limitations in their use due to a lack of standardization, complex preanalytic factors and analytical variability. ${ }^{26}$ However, the majority of laboratories usually provide MPV as a part of the full blood count. Thus, MPV is a simple marker and does not require an advanced or expensive technology. ${ }^{2}$

This study has several limitations. First, all patients were recruited from a single center, thus, the representativeness of the study population was limited, which may introduce bias into the primary findings. Second, coronary angiograms were analyzed by visual estimation only, which may overestimate a coronary lesion. ${ }^{27}$ Third, this study had a cross-sectional design, thus, the causal relationship between $\beta$-cell dysfunction and MPV could not be determined. Fourth, although we excluded patients with a history of DM, we did not perform a standard oral glucose tolerance test to exclude impaired glucose tolerance. Further research with a large sample size is required to examine the validity of HOMA2- $\beta \%$ in predicting MPV and, especially the prognosis of nondiabetic patients with CAD.

\section{Conclusion}

In conclusion, we showed that MPV was significantly higher in $\mathrm{CAD}$ patients with pancreatic $\beta$-cell dysfunction than in patients with normal $\beta$-cell function.

\section{Abbreviations}

MPV, Mean platelet volume; CAD, coronary artery disease; HOMA, Homeostatic model assessment; HOMA2- $\beta$ $\%$, Homeostatic model assessment 2 of $\beta$-cell function; IR, insulin resistance; DM, diabetes mellitus; IFG, impaired fasting glucose; BMI, body mass index; SAP, stable angina; UA, unstable angina; non-STEMI, non-STsegment elevation myocardial infarction; STEMI, STsegment elevation myocardial infarction; PCI, percutaneous coronary intervention; $\mathrm{CABG}$, coronary artery bypass graft; WBC, white blood cell; HGB, hemoglobin; PLT, platelet; TC, total cholesterol; LDL-C, low-density lipoprotein-cholesterol; HDL-C, high-density lipoproteincholesterol; TGs, triglycerides; ACEIs, angiotensinconverting enzyme inhibitors; ARBs, angiotensin receptor blockers; CCBs, calcium channel blocking agents; HbA1c, hemoglobin A1c.

\section{Data Sharing Statement}

The datasets used and/or analyzed during the current study are available from the corresponding author on reasonable request.

\section{Ethics and Informed Consent}

The study was approved by the Institutional Review Board of Beijing Anzhen Hospital (IRB number: 2018075X) and 
conducted in accordance with the principles stated in the Declaration of Helsinki. Informed consents of all participants or their legal proxies were granted.

\section{Acknowledgments}

We would like to thank American Journal Experts for providing English language editing services.

\section{Author Contributions}

All authors contributed to data analysis, drafting or revising the article, gave final approval of the version to be published, agreed to the submitted journal, and agree to be accountable for all aspects of the work.

\section{Funding}

The present work was supported by Beijing Hospital Authority Incubating Program (Code: PX2021028) and a grant from the National Natural Science Foundation of China (Code: 82070301).

\section{Disclosure}

The authors declare that they have no competing interests.

\section{References}

1. Park Y, Schoene N, Harris W. Mean platelet volume as an indicator of platelet activation: methodological issues. Platelets. 2002;13(56):301-306. doi:10.1080/095371002220148332

2. Pafili K, Penlioglou T, Mikhailidis DP, Papanas N. Mean platelet volume and coronary artery disease. Curr Opin Cardiol. 2019;34 (4):390-398. doi:10.1097/HCO.0000000000000624

3. Machin SJ, Briggs C. Mean platelet volume: a quick, easy determinant of thrombotic risk? J Thromb Haemost. 2010;8(1):146-147. doi:10.1111/j.1538-7836.2009.03673.x

4. Varol E, Akcay S, Ozaydin M, Erdogan D, Dogan A, Altinbas A. Mean platelet volume is associated with insulin resistance in non-obese, non-diabetic patients with coronary artery disease. J Cardiol. 2010;56(2):154-158. doi:10.1016/j.jjcc.2010.03.005

5. Pizzulli L, Yang A, Martin JF, Lüderitz B. Changes in platelet size and count in unstable angina compared to stable angina or non-cardiac chest pain. Eur Heart J. 1998;19(1):80-84. doi:10.1053/euhj.1997.0747

6. Tavil Y, Sen N, Yazici HU, Hizal F, Abaci A, Cengel A. Mean platelet volume in patients with metabolic syndrome and its relationship with coronary artery disease. Thromb Res. 2007;120(2):245-250. doi:10.1016/j.thromres.2006.10.005

7. Zaccardi F, Rocca B, Pitocco D, Tanese L, Rizzi A, Ghirlanda G. Platelet mean volume, distribution width, and count in type 2 diabetes, impaired fasting glucose, and metabolic syndrome: a meta-analysis. Diabetes Metab Res Rev. 2015;31(4):402-410. doi:10.1002/dmrr.2625

8. American Diabetes Association. 2. Classification and diagnosis of diabetes: standards of medical care in diabetes-2020. Diabetes Care. 2020;43(Supp1 1):S14-S31. doi:10.2337/dc20-S002

9. Baldane S, Ipekci SH, Kebapcilar A. Relationship between insulin resistance and mean platelet volume in gestational diabetes mellitus. J Lab Physicians. 2015;7(2):112-115. doi:10.4103/0974-2727.163134
10. Wallace TM, Levy JC, Matthews DR. Use and abuse of HOMA modeling. Diabetes Care. 2004;27(6):1487-1495. doi:10.2337/ diacare.27.6.1487

11. Wang T, Lu J, Shi L, et al. Association of insulin resistance and $\beta$-cell dysfunction with incident diabetes among adults in China: a nationwide, population-based, prospective cohort study. Lancet Diabetes Endocrinol. 2020;8(2):115-124. doi:10.1016/s22138587(19)30425-5

12. Sansanayudh N, Numthavaj P, Muntham D, et al. Prognostic effect of mean platelet volume in patients with coronary artery disease. A systematic review and meta-analysis. Thromb Haemost. 2015;114 (6):1299-1309. doi:10.1160/th15-04-0280

13. Handtke S, Thiele T. Large and small platelets-(When) do they differ? J Thromb Haemost. 2020;18(6):1256-1267. doi:10.1111/ jth.14788

14. Nozari Y, Parsa M, Jalali A, Ariannejad H, Shafiee A. Mean platelet volume and major adverse cardiac events following percutaneous coronary intervention. Arch Iran Med. 2019;22(4):198-203.

15. Hudish LI, Reusch JE, Sussel L. $\beta$ cell dysfunction during progression of metabolic syndrome to type 2 diabetes. $J$ Clin Invest. 2019;129(10):4001-4008. doi:10.1172/JCI129188

16. Gastaldelli A, Ferrannini E, Miyazaki Y, Matsuda M, DeFronzo RA. Beta-cell dysfunction and glucose intolerance: results from the San Antonio metabolism (SAM) study. Diabetologia. 2004;47(1):31-39. doi:10.1007/s00125-003-1263-9

17. Hunter RW, Hers I. Insulin/IGF-1 hybrid receptor expression on human platelets: consequences for the effect of insulin on platelet function. J Thromb Haemost. 2009;7(12):2123-2130. doi:10.1111/ j.1538-7836.2009.03637.x

18. Kakouros N, Rade JJ, Kourliouros A, Resar JR. Platelet function in patients with diabetes mellitus: from a theoretical to a practical perspective. Int J Endocrinol. 2011;2011:742719. doi:10.1155/2011/ 742719

19. Honing ML, Morrison PJ, Banga JD, Stroes ES, Rabelink TJ. Nitric oxide availability in diabetes mellitus. Diabetes Metab Rev. 1998;14 (3):241-249. doi:10.1002/(sici)1099-0895(1998090)14:3<241::aiddmr216>3.0.co;2-r

20. Keating FK, Sobel BE, Schneider DJ. Effects of increased concentrations of glucose on platelet reactivity in healthy subjects and in patients with and without diabetes mellitus. Am J Cardiol. 2003;92 (11):1362-1365. doi:10.1016/j.amjcard.2003.08.033

21. Franco AT, Corken A, Ware J. Platelets at the interface of thrombosis, inflammation, and cancer. Blood. 2015;126(5):582-588. doi:10.1182/ blood-2014-08-531582

22. Khodadi E. Platelet function in cardiovascular disease: activation of molecules and activation by molecules. Cardiovasc Toxicol. 2020;20 (1):1-10. doi:10.1007/s12012-019-09555-4

23. Colkesen Y, Muderrisoglu H. The role of mean platelet volume in predicting thrombotic events. Clin Chem Lab Med. 2012;50 (4):631-634. doi:10.1515/CCLM.2011.806

24. Guthikonda S, Alviar CL, Vaduganathan M, et al. Role of reticulated platelets and platelet size heterogeneity on platelet activity after dual antiplatelet therapy with aspirin and clopidogrel in patients with stable coronary artery disease. J Am Coll Cardiol. 2008;52 (9):743-749. doi:10.1016/j.jacc.2008.05.031

25. Barale C, Russo I. Influence of cardiometabolic risk factors on platelet function. Int J Mol Sci. 2020;21(2):623. doi:10.3390/ ijms21020623

26. Le Quellec S, Bordet JC, Negrier C, Dargaud Y. Comparison of current platelet functional tests for the assessment of aspirin and clopidogrel response. A review of the literature. Thromb Haemost. 2016;116(4):638-650. doi:10.1160/TH15-11-0870

27. Adjedj J, Xaplanteris P, Toth G, et al. Visual and quantitative assessment of coronary stenoses at angiography versus fractional flow reserve: the impact of risk factors. Circ Cardiovasc Imaging. 2017;10(7):e006243. doi:10.1161/circimaging.117.006243 


\section{Publish your work in this journal}

The International Journal of General Medicine is an international, peer-reviewed open-access journal that focuses on general and internal medicine, pathogenesis, epidemiology, diagnosis, monitoring and treatment protocols. The journal is characterized by the rapid reporting of reviews, original research and clinical studies across all disease areas. The manuscript management system is completely online and includes a very quick and fair peer-review system, which is all easy to use. Visit http://www.dovepress.com/ testimonials.php to read real quotes from published authors.

Submit your manuscript here: https://www.dovepress.com/international-journal-of-general-medicine-journal 